\title{
Effect of Color on Information Retention by Young Men and Women
}

\author{
Sangeeta Singg* and Chris W Mull \\ Department of Psychology, Sociology, and Social Work, Angelo State University, San Angelo, Texas, USA
}

Submission: March 8, 2017; Published: March 31, 2017

*Corresponding author: Sangeeta Singg, PhD, Professor of Psychology, Angelo State University, San Angelo, Texas 76909, USA, Tel: 1-325-223-8606; Fax: 1-325-942-2290; Email: sangeeta.singg@angelo.edu

\begin{abstract}
Most reading materials including computers have white background with black writing. The present experiment sought to examine whether color paper had an effect on college students' information retention measured as the number of words recalled. After conducting a pilot study, white, blue and yellow color papers were used in the present experiment with a sample of 117 young college students enrolled in an American Southwestern university. They were randomly divided into three experimental groups: Control group (white paper), yellow paper group, and blue paper group. The ANOVA results of the experiment showed a significant interaction between paper color and sex with regard to word recall. It was concluded that background color of instructional material can impact the students' performance positively or adversely depending on their sex. The cool colors such as blue might enhance women's learning and warm colors such as yellow might enhance men's learning.
\end{abstract}

Keywords: Color, Effects of color; Paper color (PC); Words recalled (WR); Retention; Warm colors; Cool colors

\section{Introduction}

Although past research has shown the effect of color on children's learning and performance, there is a paucity of research in this area with adults and it is fraught with complexities and conflicting findings. The research with children has some interesting and useful findings. The use of color overlays to cover the words and/or entire page has been found to help with reading speed [1,2] and to improve concentration of children [3]. The colored overlays were also found to reduce symptoms of visual stress in children who wore glasses [4].

Research with college students' performance on tests printed on different color papers has also yielded interesting, but conflicting results. Some reported no significant effects of the color on student performance [5-8] and others have found results to be significant but they contradict. One study [9] of college students reported a positive effect of red or yellow paper than white, blue, or green paper on student performance while another study [10] found students scoring higher on a midterm exam printed on blue paper than on the red paper, particularly for difficult questions. Yet another study [11] found that students taking an exam on white, blue, or green paper outscored the students taking the exam on red or yellow paper. Researchers have tried explaining these contradictory results with the help of information processing theories and sensory arousal mechanisms.
Some researchers have tried controlling the conditions and examined the effects of color on retention. A recent study [12] of 30 graduate students used a list of 20 words printed in achromatic color (black), congruent colors (e.g., grass in green color), incongruent colors (e.g., grass in purple color). Participants studied the words for ten minutes and worked on simple mathematics task for 30 minutes to prevent rehearsing the words, and then were asked to recall and write the words on a blank sheet.

The results showed higher retention rates for groups exposed to congruent and achromatic colors than those exposed to incongruent colors. Another study [13] of 120 adults found that images of natural scenes on a computer monitor in color were remembered about $5 \%$ times more than the gray-scale monochrome scenes. Effects of colored handouts on memory retention were examined by using a sample of 115 undergraduate college students in yet another study [8].

Two warm colors (Red and Yellow), two cool colors (blue and green), and white color for the control group were used as the paper colors. Twenty 1-3 syllable nouns were used for all groups to study for one minute and then they were asked to work for one minute on 3-digit multiplication task before recalling and writing as many words as they could in two minutes. The results showed no statistically significant difference for word 
recall among the groups and the reason given was the use of only bright colors. The author suggested repeating the experiment with a different design, longer time exposure, and using different colors.

Based on these suggestions and findings of children's research on color and retention, it was assumed that college students could also benefit if pretested colors were used for their reading material. Most reading materials in college including computers have white background with black writing. Because college students tend to spend an average of 59 to 71 hours per week for their study, work and domestic duties [14], any help with better retention would be beneficial. In the present experiment, retention was measured by the number of words recalled (WR).

Yellow and blue paper colors were preselected for the experiment based on the results of a pilot study explained below. Independent variables were paper color (PC) and sex. There were limited number of studies that examined the sex difference in the color and retention connection and they did not find any significant results [5,7]. Because the variable of sex has not been well explored by the previous studies, we wanted to see if sex differences would moderate the color effects. Age was controlled by using traditional students, 18 to 25 years old. The dependent variable was the number of words correctly recalled (WR).

\section{Methods}

All participants (without color blindness or visual impairment) for the pilot study and the current experiment were volunteers from the psychology classes at an American Southwestern university; they signed an approved informed consent form before participating in the study. A pilot study of 12 traditional students was conducted to select colors for the experiment. We used three pages for participants to perform three steps for the experiment. On Page 1, 20 common words of 1-2 syllables such as "light" and "come" were listed for participants to study for two minutes.

On Page 2, 24 simple arithmetic problems were listed for participants to solve for two minutes to prevent the rehearsal effect. Page 3 was a blank page for the participants to write as many words as they could recall from Page I within two minutes. The participants were randomly assigned to four groups with words printed on four light color papers: pink, yellow, blue and green. These light colors are commonly used to print handouts and examinations. They were run through the three steps listed above (study the 20-word list, work on arithmetic tasks, and then recall and write as many words as possible).

Blue and yellow color papers yielded the best word recall (average word recall: yellow $=16$, blue $=15.5$, pink $=12$, and green $=11$ ). Thus, white, blue and yellow color papers were used in the experiment with a sample of 117 traditional students (age $\mathrm{M}=20.26, \mathrm{SD}=4.76 ; 67 \%$ Caucasian; 53\% men). They were randomly divided into three groups: Control Group (White Paper: CG), Yellow Paper Group (YG), and Blue Paper Group (BG). After signing the informed consent form, they completed a General Information Questionnaire and were then asked to study the 20 word list printed on their group color paper for two minutes, work on arithmetic tasks for two minutes, and recall and write down as many words as possible on the blank paper within two minutes.

\section{Results}

Table 1: Mean word recall (WR), standard deviations, and $F$ values for Paper Color (PC) and Sex.

\begin{tabular}{|c|c|c|c|}
\hline Variable & M & SD & F \\
\hline $\begin{array}{c}\text { Paper Color } \\
\text { (PC) }\end{array}$ & & 3.03 & \\
\hline White & 15.35 & 3.3 & \\
\hline Yellow & 14.96 & 3.23 & \\
\hline Blue & 15.89 & 3.03 & 2.56 \\
\hline Sex & 15.89 & 3.45 & \\
\hline Men & 14.94 & 2.89 & \\
\hline Women & 15.15 & 3.26 & \\
\hline PC x Sex & 15.56 & 2.1 & \\
\hline White PC/Men & 17.04 & 4.28 & \\
\hline $\begin{array}{c}\text { White PC/ } \\
\text { Women }\end{array}$ & 12.9 & 3.71 & \\
\hline Yellow PC/Men & 15.17 & 2.61 & \\
\hline $\begin{array}{c}\text { Yellow PC/ } \\
\text { Women }\end{array}$ & 16.38 & & \\
\hline Blue PC/Men & & & \\
\hline $\begin{array}{c}\text { Blue PC/ } \\
\text { Women }\end{array}$ & & & \\
\hline
\end{tabular}

The $3 \times 2$ factorial ANOVA results Table 1 showed no significant main effect of PC on WR, F 2,111 = .88, ns. The main effect of Sex on WR was also not significant, F1, $111=2.56$, ns. However, a significant interaction was found between PC and Sex with regard to WR, F2, $111=7.34, \mathrm{p}<.001$ ). The Tukey/Kramer procedure was used for pair wise comparisons. A significant difference was found between men and women in the Yellow PC Group ( $\mathrm{t}=13.77, \mathrm{p}<0.05)$. Men had a greater mean WR with the Yellow PC (17.04; SD = 2.10) than did Women (12.9; SD = 4.28). Also a significant difference was found between men and women in the Blue PC Group ( $\mathrm{t}=8.54, \mathrm{p}<0.05)$; Women showed a greater mean WR $(16.38 ; \mathrm{SD}=3.71)$ than did men $(15.17 ; \mathrm{SD}=$ 2.61). No other pair wise comparisons were significant.

\section{Discussion}

In this experiment, paper color by itself did not yield any significant result which coincides with previous research findings [5-8]. However, as expected, men and women differed significantly in their word recall with regard to yellow and blue paper colors. Men did better than women with the yellow color paper while women did better than men with the blue color 
paper. Interestingly among all subgroups, mean word recall was the highest (17.04) for men using yellow color paper and the mean word recall was the lowest (12.90) for women using yellow color paper. It appears that sex indeed is a moderator for this effect.

Some perceptual and psychological effects have been described by the color theory [15]. Blue is considered "cool" color which is restful and also associated with comfort and security, while yellow is considered a "warm" color seen as active, strong and stimulating. Along the similar lines in another study [16], both men and women exposed to yellow color reported higher levels of anxiety than those exposed to blue color.

In our study, the stimulating color such as yellow might have enhanced men's word recall because the arousal is considered culturally a positive condition by men in Texas, whereas women might see yellow as anxiety producing and interfering with their word recall. This assumption also coincides with another study's finding [17] that women prefer soft colors while men prefer bright colors, although the study examined the role of color in perception of attractiveness. Thus, the learning and retention researchers using colors need to consider the hypothesis of the "interference in performance" due to the effects of colors on one's mind and emotions [5].

The major conclusion of the present experiment is that background color has implications for learning of material for college students depending on their sex. Cool color paper such as blue should be used for women and warm color paper such as yellow might be better for men. This color impact might also generalize to computer backgrounds and other instructional materials for college students. Professors often print examinations on two different colors of paper and distribute them alternately to prevent cheating.

Our finding suggests that the professors should be cognizant of the color impact on retention while selecting the instructional material background colors for their students because the colors might influence their performance positively or adversely depending on their sex. There are many loose ends in the color and retention connection research and much more research is needed to make any definitive conclusions. Because we had a sample of convenience, our findings should be considered with caution. However, the current state of many conflicting findings points to the methodological differences among studies and their limitations that needs to be examined. Not withstanding, there is enough evidence about the color effects on retention which demands further research.

\section{References}

1. Ludlow A, Wilkins A, Heaton P (2006) The effect of coloured overlays on reading ability in children with autism. Journal of Autism and Developmental Disorders 36(4): 507-516.

2. Waldie M, Wilkins J (2004) How big does a coloured overlay have to be? Ophthalmic and Physiological Optics 24(1): 57-60.

3. Wilkins AJ, Lewis E, Smith F, Rowland E, Wendy T (2001) Coloured overlays and their benefit for reading. Journal of Research in Reading, 24(1): 41-64.

4. Smith L, Wilkins A (2007) How many colours are necessary to increase thereading speed of children with visual stress? A comparison of two systems. Ophthalmic and Physiological Optics 30(3): 332-343.

5. Michael WB, Jones RA (1955) The influence of color of paper upon scores earned on objective achievement examination. The Journal of Applied Psychology 39(6): 447-450.

6. Martinez JV, Oberle CD, Thompson JG (2010) Effects of color on memory encoding and retrieval in the classroom. American Journal of Psychological Research 6(4): 24-31.

7. Tal IR, Akers KG, Hodge GK (2008) Effect of paper color and question order on exam performance. Teaching of Psychology 35(1): 26-28.

8. Huchendorf L (2007) The effects of color on memory. UW-L Journal of Undergraduate Research X, 1-4.

9. Jacobs KW, Blandino SE (1992) Effects of color of paper on which the Profile of Mood States is printed on the psychological states it measures. Perceptual \& Motor Skills 75(1): 267-271.

10. Sinclair RC, Soldat AS, Mark MM (1998) Affective cues and processing strategy: color-coded examination forms influence performance. Teaching of Psychology 25(2): 130-132.

11.SkinnerN (2004) Differential test performance from differently colored paper: white paper works best. Teaching of Psychology 31(2): 111-113.

12. Olurinola 0 , Tayo O, Onabanjo 0 (2015) Colour in learning: it's effect on the retention rate of graduate students. Journal of Education and Practice 6(14): 1-5.

13. SpenceI, Wong P, Rusan M, Rastegar N (2006) How color enhances visual memory for natural scenes. Psychological Science 17(1): 1-6.

14. Lowe J, Gayle V (2007) Exploring the work/life/study balance: the experience of higher education students in a Scottish further education college. Journal of Further and Higher Education 31(3): 225-238.

15. Ballast DK (2002) Interior design reference manual. Professional Pub, Belmont, CA, USA.

16. Kwallek N, Lewis C, Robbins A (1988) Effects of office interior color on workers 'mood and productivity. Perceptual \& Motor Skills 66(1): 123-128.

17. Radeloff DJ (1990) Role of color in perception of attractiveness. Perceptual and Motor Skills, 71(1): 151-160. 


\section{Your next submission with Juniper Publishers} will reach you the below assets

- Quality Editorial service

- Swift Peer Review

- Reprints availability

- E-prints Service

- Manuscript Podcast for convenient understanding

- Global attainment for your research

- Manuscript accessibility in different formats ( Pdf, E-pub, Full Text, Audio)

- Unceasing customer service

Track the below URL for one-step submission https://juniperpublishers.com/online-submission.php 